\title{
Centrosome-phagy: implications for human diseases
}

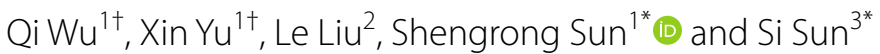

\begin{abstract}
Autophagy is a prominent mechanism to preserve homeostasis and the response to intracellular or extracellular stress. Autophagic degradation can be selectively targeted to dysfunctional subcellular compartments. Centrosome homeostasis is pivotal for healthy proliferating cells, but centrosome aberration is a hallmark of diverse human disorders. Recently, a process called centrosome-phagy has been identified. The process involves a panel of centrosomal proteins and centrosome-related pathways that mediate the specific degradation of centrosomal components via the autophagic machinery. Although autophagy normally mediates centrosome homeostasis, autophagy defects facilitate ageing and multiple human diseases, such as ciliopathies and cancer, which benefit from centrosome aberration. Here, we discuss the molecular systems that trigger centrosome-phagy and its role in human disorders.
\end{abstract}

Keywords: Centrosome, Autophagy, Ciliopathies, Aging, Cancer

\section{Centrosome composition and duplication}

The centrosome is an evolutionarily conserved cylindrical organelle normally localized around the nuclei. It is composed of a pair of centrioles, which consist of fibres connecting their proximal ends and an amorphous cloud of different proteins surrounding the centriole pair called pericentriolar material (Fig. 1a) (PCM) [1]. A signature feature of the centriole is that nine sets of microtubules are arranged in a radially symmetrical manner at the organelle periphery [2]. The centriole is a polarized entity, with proximal and distal regions that differ notably in the number of microtubules they harbour. Thus, nine microtubule triplets, dubbed the A-, B-, and $\mathrm{C}$-microtubules within each triplet, are present in the proximal region. The $\mathrm{C}$-microtubule is absent from the

\footnotetext{
*Correspondence: sun137@sina.com; 59333173@qq.com

${ }^{\dagger}$ Qi Wu and Xin Yu contributed equally to this work

1 Department of Breast and Thyroid Surgery, Renmin Hospital of Wuhan University, 238 Ziyang Road, Wuhan 430060, Hubei, People's Republic of China

${ }^{3}$ Department of Clinical Laboratory, Renmin Hospital of Wuhan University, 238 Ziyang Road, Wuhan 430060, Hubei, People's Republic of China

Full list of author information is available at the end of the article
}

distal region, so nine sets of microtubule doublets are present there. Furthermore, in the proximal region, the A-microtubule of one triplet and the $\mathrm{C}$-microtubule of the adjacent triplet are connected by an A-C linker [3]. Other striking features present in mature centrioles are the subdistal and distal appendages. The latter are essential for docking beneath the plasma membrane upon templating the ciliary or flagellar axoneme [4]. Outside the centriole microtubule wall lies a cloud of proteins collectively forming the PCM, which is critical for the nucleation of cytoplasmic microtubules [5]. Another striking nine-fold symmetrical structure is the cartwheel present in the proximal-most $\sim 100 \mathrm{~nm}$ of the procentriole, which elongate and develop as the new daughter centriole prior to mitosis [6]. The cartwheel can be observed before centriole microtubules during the assembly process in some systems and is essential for centriole biogenesis in most organisms [6], suggesting that it may impart the signature nine-fold radial symmetry to the entire organelle. The PCM supplies sites for microtubule nucleation, thus determining the number and composition of microtubules during the cell cycle. Therefore, all microtubulerelated functions, including cell division, cell shape,

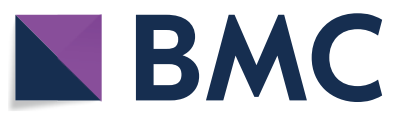

c) The Author(s) 2021. This article is licensed under a Creative Commons Attribution 4.0 International License, which permits use, sharing, adaptation, distribution and reproduction in any medium or format, as long as you give appropriate credit to the original author(s) and the source, provide a link to the Creative Commons licence, and indicate if changes were made. The images or other third party material in this article are included in the article's Creative Commons licence, unless indicated otherwise in a credit line to the material. If material is not included in the article's Creative Commons licence and your intended use is not permitted by statutory regulation or exceeds the permitted use, you will need to obtain permission directly from the copyright holder. To view a copy of this licence, visit http://creativeco mmons.org/licenses/by/4.0/. The Creative Commons Public Domain Dedication waiver (http://creativecommons.org/publicdomain/ zero/1.0/) applies to the data made available in this article, unless otherwise stated in a credit line to the data. 

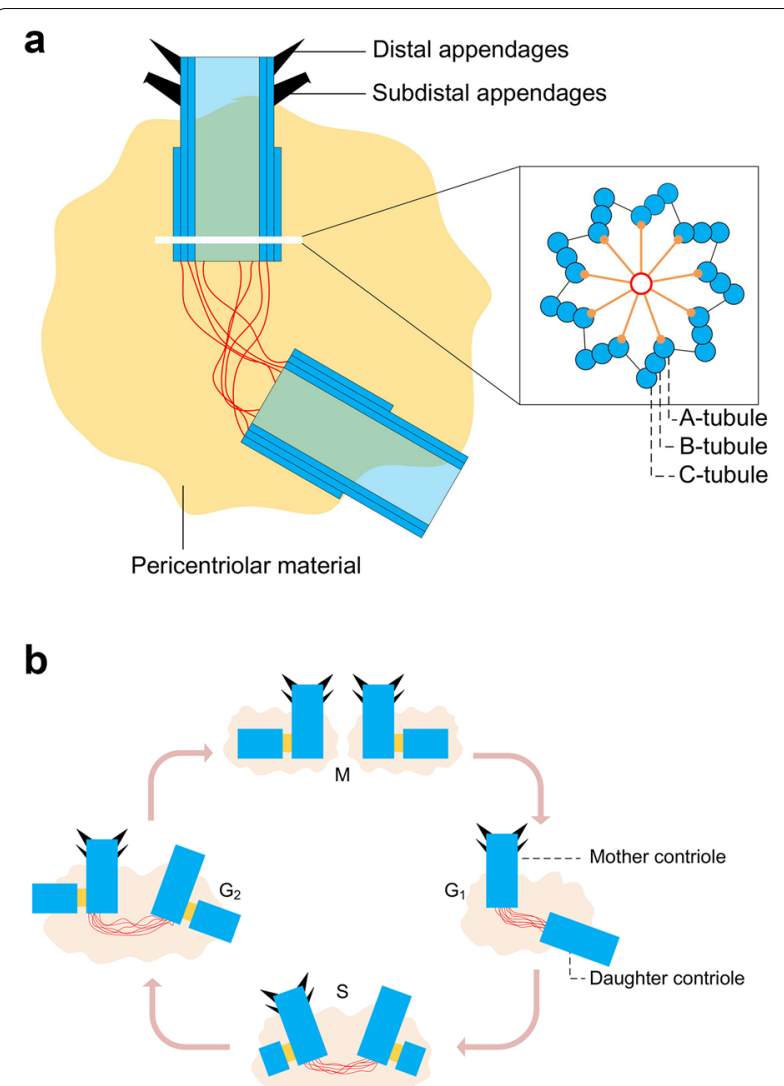

Fig. 1 Centrosome composition and duplication. a The centrosome is composed of a pair of centrioles, which consist of fibres connecting their proximal ends and PCM surrounding the centriole pair. Nine microtubule triplets, dubbed the A-, B-, and C-microtubules within each triplet, are present in the proximal region of centrioles. The C-microtubule is absent from the distal region. In the proximal region, the A-microtubule and the $\mathrm{C}$-microtubule are connected by an $\mathrm{A}-\mathrm{C}$ linker. Other striking features present in mature centrioles are the subdistal and distal appendages; $\mathbf{b}$ Cells in the G1 phase contain two centrioles termed the mother and daughter centrioles. Towards the G1-to-S transition, a procentriole starts to assemble. During the $S$ and $\mathrm{G} 2$ phases, each procentriole remains engaged in this configuration with its parental centriole and elongates. Towards the end of $\mathrm{G} 2$, the flexible link between the two parental centrioles is severed, allowing the two centrosomes to separate and govern assembly of the bipolar mitotic spindle

polarity, motility and adhesion, are coordinated by centrosomes [7].

As with deoxyribonucleic acid (DNA) replication, the duplication of the centrosome is semi-conservative and is coupled with cell cycle progression in most cases, thus ensuring that each cell is endowed with the accurate complement of chromosomes and the correct number of two centrioles (Fig. 1b) [8]. During this process, the size of the centrosome is strictly regulated. Cells in the G1 phase contain two centrioles termed the mother and daughter centrioles, which are linked through a flexible structure connecting their proximal ends [9]. Towards the G1-to$\mathrm{S}$ transition, a procentriole starts to assemble $\sim 100 \mathrm{~nm}$ away from the microtubule wall of the proximal region of each parental centriole, almost orthogonally to the wall. During the S and G2 phases, each procentriole remains engaged in this configuration with its parental centriole and elongates to $\sim 400 \mathrm{~nm}$. Towards the end of G2, the flexible link between the two parental centrioles is severed, allowing the two centrosomes, each with a procentriole/centriole pair, to separate and govern assembly of the bipolar mitotic spindle [10]. During mitosis, each procentriole disengages from its parental centriole and loses the cartwheel, which is likely targeted for degradation. The two resulting centriolar cylinders in each daughter cell are then linked through their proximal ends via a flexible structure, thus completing the duplication cycle [9]. Together, these observations suggest that, in proliferating cells, the parental centriole provides a preferential scaffold that somehow favours the local assembly of a single and correct procentriole, thus ensuring faithful centriole duplication [10].

\section{Centrosome-phagy contributes to centrosome homeostasis}

Centrosome homeostasis not only ensures the normality of centrosome number and structure, but also maintains the normal assembly process and function of centrosome, which is an essential factor for preserving cellular homeostasis and preventing disease onset [11]. And the deregulation of centrosome homeostasis is a hallmark feature of many human diseases [12]. Centrosome homeostasis is affected by many factors. For example, nuclear pore complex (NPC)-associated proteins Nup133 and Nup358 (also known as RanBP2) are involved in the control of centrosome position, and their absence lead to the failure of centrosome tethering to the nucleus at the G2/M transition, which is required for timely establishment of a properly positioned mitotic spindle [13, 14]. Overexpression or underexpression of some centrosome proteins like Polo-like kinase 4 (PLK4) and centrosomal P4.1 associated protein (CPAP, also known as CenpJ) contribute to changes in the structure and quantity of centrosomes $[15,16]$. And electron transport chain dysfunction (mitochondrial DNA depletion or electron transport chain inhibition) [17], failure of cytokinesis, mitotic slippage, cell-cell fusion and excessive centrosome duplication can lead to centrosome amplification [18]. In addition, recent studies have shown that autophagy is involved in regulating centrosome homeostasis [19-21].

Macroautophagy (hereafter referred to as autophagy) is a catabolic process. The formation of a double membrane 
phagophore (also known as an isolation membrane) is the key to the process of autophagy. This membrane forms an autophagosome after it elongates and closes, engulfs cellular material and transports it to lysosomes, and eventually the contents of the autophagosome are degraded and recycled [22]. Autophagosome formation is initiated by the Unc-51 like autophagy activating kinase (ULK) protein kinase complex [23]. The ULK protein kinase complex phosphorylates and activates the autophagyrelated protein 14 (ATG14)-Beclin1-phosphatidylinositol 3-phosphate (PI3P) kinase complex, which resulting in a PI3P pool at autophagosome formation sites on the endoplasmic reticulum (ER) and recruited PICP-binding effectors double FYVE-containing protein 1 (DFCP1) and WD repeat domain phosphoinositide-interacting protein (WIPI) proteins. ATG12-5-16L1 complex is recruited to the phagophore membrane by WIPI2b, and it mediates the lipidation of cytosolic ATG8 proteins by the lipid phosphatidylethanolamine and membrane association [24]. Mammalian ATG8 proteins comprise two subfamilies, namely light chain $3 \mathrm{~s}$ (LC3s, including LC3A, LC3B and LC3C), and gamma-aminobutyric acid receptor-associated protein (GABARAPs, including GABARAP, GABARAP-like 1 and GABARAP-like 2), and play a crucial role in the formation and closure of the phagophore and the fusion of autophagosome and lysosome $[25,26]$. Autophagosomes will be reduced in size and can not fuse with lysosomes after knocking out LC3s or GABARAPs. Moreover, the depletion of GABARAP inhibits the autophagy flux induced by starvation, and the depletion of LC3 leads to a decrease in cellular basal autophagy (autophagy level under non-induced conditions) [27]. Besides, the interaction between GABARAP and ATG2A/ATG2B is essential for phagophore closure [28]. Originally, autophagy was considered a nonselective process. However, increasing evidence suggests that there is another alternative type of autophagy called chaperone-mediated autophagy (CMA) that can deliver specific targets (such as proteins and organelles) to autolysosomes, leading to the degradion of these targets [22]. Specific autophagy receptors (such as P62, neighbor of BRCA1 gene 1 protein (NBR1)) and LC3s/GABARAPs are essential in this process. Autophagy receptors bind to cargo for degradation, and to LC3s/GABARAPs on the autophagosome membrane through the LC3-interacting region (LIR) [22]. Therefore, the genetic inactivation of autophagy receptors will cause the target protein or organelle to be unable to turnover without affecting other forms of selective or non-selective autophagy [22]. Evidence showed that loss of Beclin 1, a component of the autophagy machinery, increased the frequency of centrosome abnormalities, including increased centrosome number, indicating that autophagy plays a crucial role in maintaining the stability of centrosome [19]. Similarly, centrosome amplification disorganized autophagosome trafficking to lysosomes, resulting in an accumulation of autophagosomes [20], suggesting that autophagic flux was suppressed under centrosome-amplified conditions to prevent extra centrosomes from being degraded. Therefore, the concept of centrosome-phagy is proposed to describe the process of consumption of centrosome or centrosome components by selective autophagy. Nevertheless, the potential mechanism of centrosome-phagy has been described with the identification of the receptors needed for targeting centrosome fragments to the lysosome via a classical autophagy pathway (Fig. 2). To date, several centrosome-resident proteins have been identified to be degraded via selective centrosome-phagy or regulate centrosome-phagy, and multiple pathways connect autophagy and centrosome homeostasis.

\section{Centrosome-resident proteins as receptors for selective centrosome-phagy Cep63}

Centrosomal protein 63 (Cep63) was first identified as a centrosome protein component by proteomic analysis of the centrosome and has been shown to function in the initial step of centriole duplication [29, 30]. Cep63 regulates mother-centriole-dependent centriole duplication by binding to Cep 152 and then recruiting PLK4 to activate centriole biogenesis [29]. Likewise, Cep63 and Cep 152 collaborate to promote the accumulation of essential centriole duplication factors upstream of SAS-6 (Spindle assembly abnormal protein 6 homolog) recruitment and procentriole formation to ensure efficient centriole duplication [30]. In this model, Cep192 is essential for the recruitment of Cep63 and Cep152 to the centrosome. Subsequently, knockdown of Cep63 and Cep152 could abolish homodimerized SAS-6 recruitment to the centrosome [30]. SAS-6 is recruited to the centrosome in $S$ phase and forms the cartwheel structure based on the procentriole to act in centriole biogenesis [31]. Hence, Cep63 plays a valuable role in the regulation of centriole duplication.

A recent study indicated that Cep63 could be degraded by autophagy to regulate the number of centrosomes [32]. Moreover, the increase in Cep63 dots and multiple centrosomes found in $\mathrm{p} 62^{-1-}$ mouse embryonic fibroblasts (MEFs) indicates a direct interaction between Cep63 and p62 (an adaptor or cargo receptor for autophagic degradation). Ultimately, autophagy engulfs and digests Cep63 dots to maintain centrosome homeostasis [32]. In addition, Cep63 is required for the centrosome localization of UV-irradiation-resistance-associated gene (UVRAG) [33]. UVRAG, as an autophagic initiator, primarily functions via interaction with Beclin 1 to activate the 


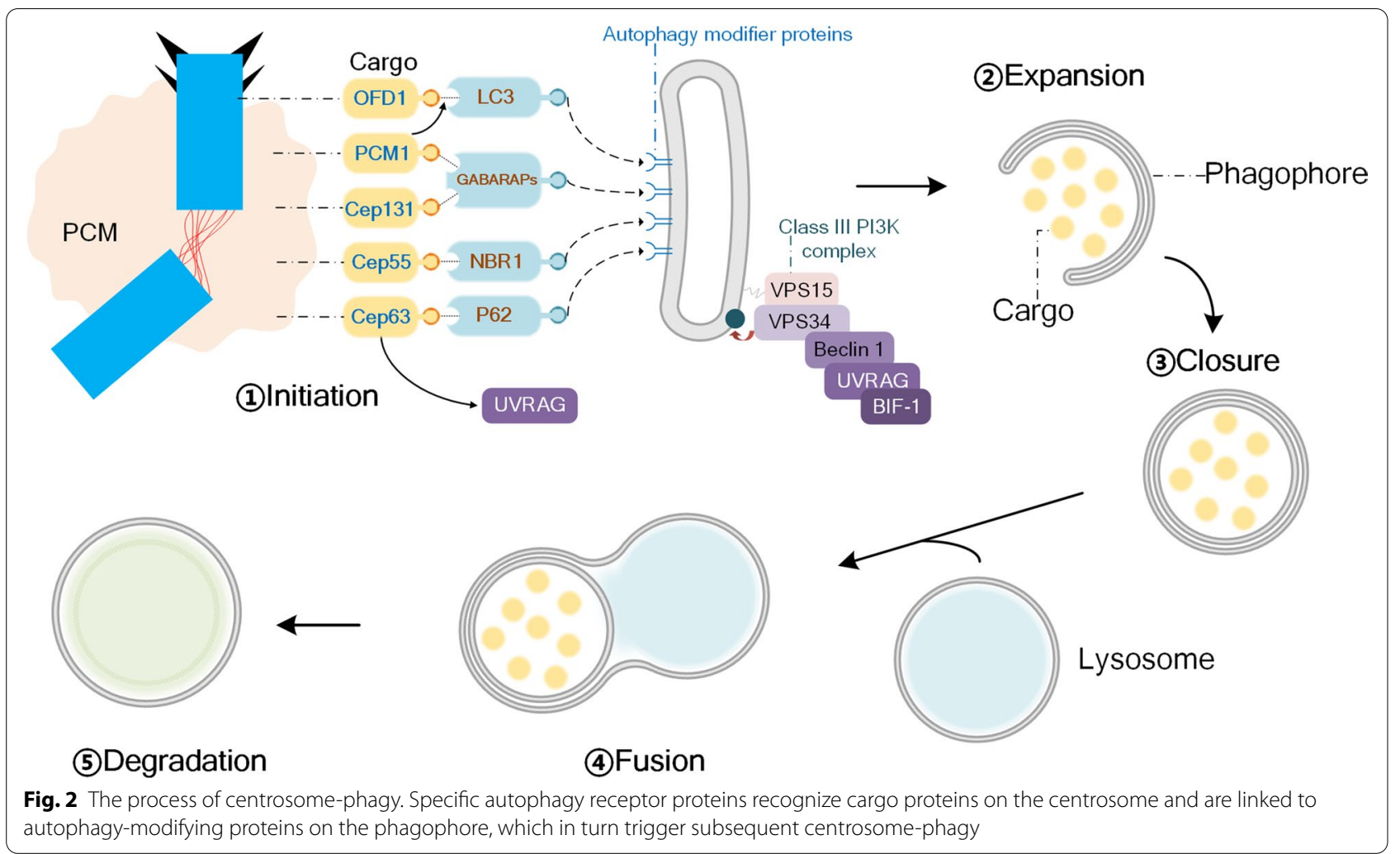

autophagy-related class III phosphoinositide 3-kinase (PI3K) complex [34]. Furthermore, disruption of the association between UVRAG and centrosomes leads to centrosome abnormalities and aneuploidy in a manner independent of its role in autophagy signalling [33]. Although there is no evidence at the present moment, the autophagy-mediated degradation of Cep63 may also maintain the centrosome homeostasis by regulating the autophagy-independent function of UVRAG. Given the central role of UVRAG in centrosome and autophagic clearing, its effect merits further exploration.

\section{PCM1}

PCM1 has been identified as a centrosomal protein and provides a structural scaffold for the assembly of centriolar satellites (CSs) [21]. PCM1 is a large $(\sim 230 \mathrm{kDa})$ coiled-coil-containing protein. It can self-oligomerize and bind other CS proteins, such as the E3 ligase mind bomb 1 (MIB1) [35] and the deubiquitinase Ubiquitin Specific Peptidase 9 X-Linked (USP9X) [36]. There are different CS populations that contain different proteins; they colocalize with and bind to PCM1 and require PCM1 for their pericentrosomal localization. Moreover, PCM1 appears to regulate the actin-related proteins $2 / 3$ (Arp2/3) complex and Wiskott-Aldrich syndrome protein (WASP) and Scar homologue (WASH) recruitment to the centrosome to mediate the centrosomal actin network [37].

Recently Holdgaard et al. identified PCM1-mediated selective autophagy of CSs and named it doryphagy [38, 39]. Interestingly, PCM1 interacts with GABARAPs but not LC3 and is then degraded by autophagy. GABARAPs are located on the pericentriolar matrix, and this dynamic pool contributes to autophagosome formation [39]. Previously, the PCM1 LIR motif was shown to be required for PCM1 colocalization with autophagosomes via direct interaction with GABARAPs [40]. This process does not depend on MIB1-mediated ubiquitylation [41]. Furthermore, PCM1 increases the formation and flux of GABARAPs/WIPI2/p62-positive autophagosomes without affecting LC3B-positive autophagosome formation [40].

Moreover, the study of Tang et al. showed that the interaction between LC3 and OFD1 (oral-facial-digital syndrome 1) was enhanced by PCM1 through autophagic processes to stimulate rapid degradation of OFD1 in MEFs [42]. OFD1 is the gene underlying the human disease oral-facial-digital syndrome type 1 (OFD1). An $\mathrm{X}$-linked ciliopathy characterized by morphological abnormalities and renal cysts, as well as Joubert syndrome and Simpson-Golabi-Behmel syndrome type 2 , can be caused by OFD1 abnormalities [43, 44]. OFD1 
is located at the distal end of the centriole and the central granular satellite, so it is required for the formation of distal attachments, intraflagellar transport protein 88 (IFT88) recruitment and primary cilia formation and interacts with the human ciliary body disease-related proteins PCM1, Cep290, and Bardet-Biedl syndrome 4 (BBS4)[45]. Therefore, PCM1 is viewed as a specific CS receptor, and it is selectively recognized and degraded through autophagy to maintain centrosome integrity and accurate mitosis.

\section{Cep131 and Cep55}

There are some other structural proteins of the centrosome involved in centrosome-phagy. First, Cep131 $(\sim 131 \mathrm{kDa}$, also called AZI1) is an evolutionarily conserved centriolar satellite protein associated with genomic stability maintenance and cilia formation [46, 47]. As a novel substrate of PLK4, Cep131 is phosphorylated to facilitate recruitment of SCL-interrupting locus protein (STIL) to the centriole, leading to centrosome amplification and cancer development [48]. Intriguingly, CEP131 is an ubiquitinated protein, and Cep131 stabilized by the deubiquitinase activity of USP9X promotes centrosome biogenesis and breast carcinogenesis [49]. Recently, Cep131 was shown to associate with LC3 in U2OS cells, as demonstrated by immunoprecipitation [42], suggesting that Cep131 may participate in the autophagic response. Likewise, Cep131 also interacted with GABARAPs but not LC3 in ATG8-inducible MCF7 cells, and bafilomycin A1, an autophagic inhibitor, led to the accumulation of Cep131, indicating that Cep131 is also degraded by autophagy under autophagy-inducing conditions [41]. Consistently, Cep55 localizes to the centrosome in interphase cells and is recruited to the midbody during cytokinesis. Mechanistically, Cep55 binds to the autophagic receptor NBR1 and is further tethered to the site of autophagosomal engulfment [50].

\section{The proteins as regulators for selective centrosome-phagy PLK1}

Polo-like kinase 1 (PLK1) is the most frequently investigated PLK protein and has multiple effects on the cell cycle: coordinates the centrosome and cell cycles, controls mitotic initiation and the G2/M checkpoint, facilitates DNA replication, and plays multiple roles in spindle assembly and chromosome segregation [51].

It is worth considering that current research shows that PLK1 has a paradoxical role in autophagy modulation. For instance, PLK1 has been confirmed to induce autophagy in multiple cells. PLK1 is upregulated by natural neuroprotective autophagy enhancer corynoxine (Cory) in N2a neuroblastoma cell. In addition, Cory downregulated ribosomal protein S6 kinase and polypeptide 1 (p70S6K) to enhance autophagy, and the effect was dramatically diminished by inhibiting PLK1 [52]. Furthermore, Ruf et al. used Hela cells to demonstrate that PLK1 directly phosphorylates the component regulatory-associated protein of mTOR (RAPTOR, also known as RPTOR) in mechanistic target of rapamycin complex 1 (mTORC1) at lysosomes and inhibits the activity of mTORC1, thereby activating autophagy [53]. Hence, overactivation of PLK1 stimulates the autophagic response by decreasing the function of mTORC1 at lysosomes. In contrast, the PLK1 pharmacological inhibitors RO3280 and BI2536 induce autophagy to reduce tumour growth in androgen-insensitive (AI) castration-resistant prostate cancer $(\mathrm{PCa})$ cells LNCaP-AI and acute promyelocytic leukemia NB4 cells $[54,55]$. On the mechanism, both inhibitors contribute to the dephosphorylation of mTOR, which further increases the autophagic response.

The potential reason for these controversial results may be the differences in different cell types or in the length of cell cycle arrest (Fig. 3). In the study of Ruf et al., PLK1 was inhibited by BI2536 in the short term $(30 \mathrm{~min})$ and combined with amino acid starvation [53]. Therefore, it mainly affects cells in interphase. During mitotic interval, PLK1 binds to mTOR and localizes on the surface of lysosomes, so overactivation of PLK1 causes the mTORC1 complex to disengage from lysosomes and thus activate autophagy. In the studies of Deeraksa et al. and Tao et al., PLK1 was inhibited in the long term (5 days and 8 days, respectively) [54, 55], which also inhibited PLK1 during mitosis. Based on the above data, we speculated that when cells are in mitotic phase, PLK1 is mainly located in the centrosome to ensure normal replication and division of the centrosome during mitosis. Inhibition of PLK1 will lead to centrosome abnormalities and mitotic errors, which further result in abnormal transcriptional pressure and protein aggregation, and activate autophagy-dependent degradation processes. The complex roles of PLK1 in autophagy regulation require further investigation.

\section{p53}

The p53 tumour suppressor is considered the "guardian of ploidy", acting in the prevention of centrosome structural or quantitative abnormalities through its transcriptional function [56-59]. However, the role of P53 located at the centrosome is still unclear. A previous study showed that P53 accumulates in centrosomes with simultaneous phosphorylation of Ser15 when TIG-1 human fibroblasts undergo cellular aging induced by serial passaging or oxidative stress [60]. Meanwhile, ataxia telangiectasia mutated (ATM) phosphorylates p53 Ser15 on discrete cytoplasmic p53 foci located at the centrosome of normal human lymphoblastoid cells (AHH1) [61]. 


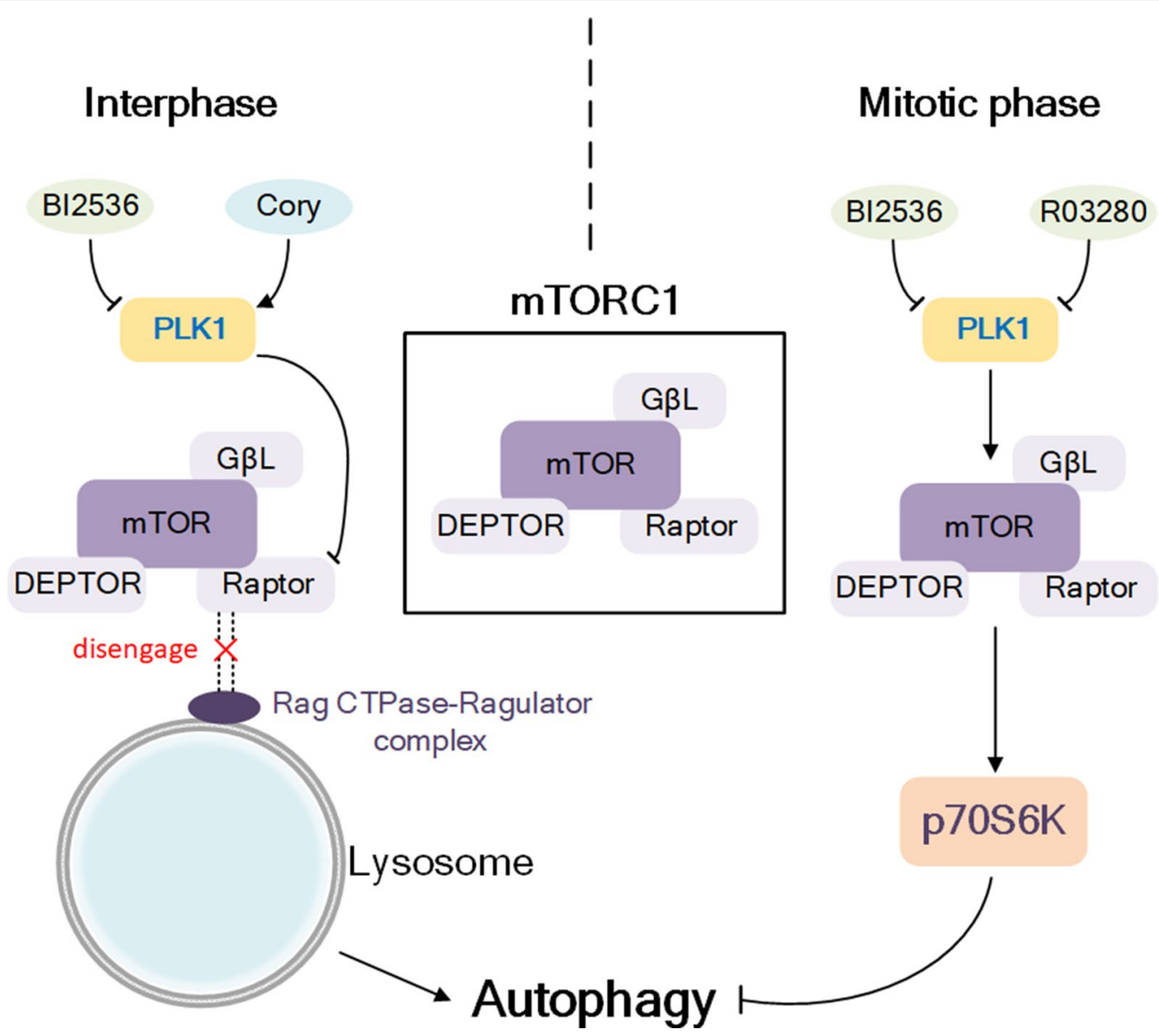

Fig. 3 Different effects of PLK1 on autophagy in interphase and mitotic phase. In interphase, PLK1 can promote autophagy by phosphorylating Raptor to cause mTORC1 to disengage from lysosome. In mitotic phase, PLK1 promotes mTORC1 leading to up-regulation of p70S6K expression, thereby inhibiting autophagy

It has long been known that p53 is located on centrosomes, but the function of p53 in this organelle is poorly understood. Recent studies have shown that selective impairment of p53 located at the centrosome can lead to centrosome fragmentation (Fig. 4). The essential effector p53-binding protein 1 (53BP1) in the mitotic surveillance pathway will bind to centrosomal P53, and the mitotic surveillance pathway will prevent human cells from growing under conditions with a high risk of making mitotic errors or accumulating numerous chromosome defects [62]. Evidence shows that induction of P53 and G1 arrest after centrosome depletion will be impaired by as deletion of either of 53BP1 or deubiquitinase ubiquitin-specific protease 28 (USP28), which are both essential components acting upstream of P53. 53BP1 is recruited to P53 through the BRCA1 C terminus (BRCT) domain, and the interaction between the BRCT domains of the 53BP1 and P53 is necessary for centrosome monitoring pathways other than normal DNA damage response (DDR) [63]. The main function of P53-53BP1 complex centrosome localization is to stabilize the structure of centrosome and ensure its normal function. Moreover, under conditions of strong external stimuli such that P53-53BP1 complex cannot guarantee the stability of centrosome structure, nuclear translocation of P53 will be induced to stimulate autophagic activity, and then degrade abnormal centrosome proteins to ensure the centrosome homeostasis [60]. In addition, p53 is demonstrated to guarantee correct spindle pole positioning and chromosome segregation by stimulating centrosome separation [59]. Ultimately, overexpression of Cep55 is discovered in the majority of human cancers with inactivation of p53. p53 reduces the protein stability of Cep55 and then downregulates the expression of Cep55 by inhibiting the activity of PLK1 [57]. Thus, it is possible that the phosphorylation and accumulation of p53 in the centrosome is the pivotal event that guarantees the normal function of the centrosome and exerts an anti-tumour effect. Importantly, p53 also functions as a well-studied connector linking autophagy and 


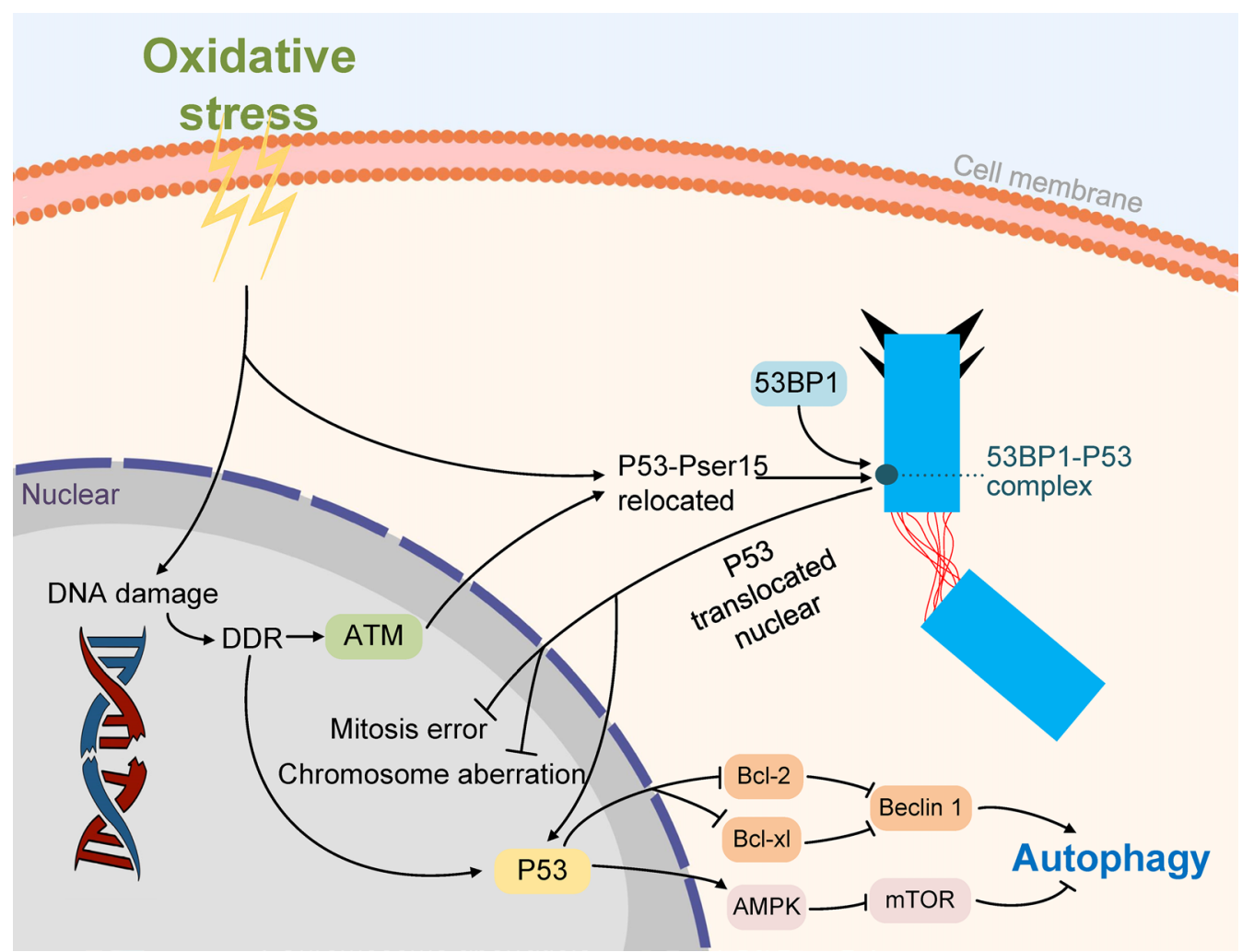

Fig. 4 The function of p53 centrosome localization and the effect of p53 on autophagy. Under oxidative stress, P53 accumulates in the centrosome and binds to $53 \mathrm{BP} 1$ to form a complex to stabilize the structure of the centrosome and ensure its normal function. Under strong external stimulation conditions, the P53-53BP1 complex dissociates and P53 nuclear translocation will be induced to stimulate autophagy to maintain centrosome homeostasis and prevent mitosis error and chromosome aberration

stress-induced cell cycle responses. After DNA damage, nuclear p53 activates various autophagy-related signalling pathways to induce autophagy, including activating the AMP-activated protein kinase (AMPK)-mTOR pathway and releasing Beclin 1 from inhibitory interactions with B-cell lymphoma-2 (Bcl-2) and B-cell lymphomaextra large (Bcl-XL) [64]. p53 induces autophagy to remove abnormal centrosome proteins, which may be a way to ensure normal mitosis of cells. Therefore, further research is needed to understand whether centrosomal p53 induces autophagy and how this process is regulated.

\section{Insights into centrosome-phagy-related human disorders}

Centrosome defects can be roughly divided into numerical abnormalities and structural abnormalities, of which structural abnormalities include centriole structural defects and PCM component defects [12]. As mentioned above, centrosome-phagy regulates the numerical abnormalities and structural abnormalities of the centrosome by degrading the centrosome or specific centrosome components. Based on the complexity and importance of centrosome function [65], centrosome-phagy is associated with various human disorders, including ciliopathies, ageing and cancer (Table 1).

\section{Ciliopathies}

The centrosome is closely related to ciliogenesis. Similar to centriole, cilia are nine-fold symmetrical microtubulebased cylindrical structures and extend from the surface of the cell [66]. Ciliogenesis mainly occurs in the G1-S phase, when the mother centriole matures into basal body and migrates to the cell surface. Then the distal appendages of the basal body directly interacts with the plasma membrane to form the ciliary membrane, and the doublet microtubules of basal body began to elongate to form axons extending cell periphery to form the cilia [67]. Thus, centrosome defects can lead to]disorders of ciliogenesis, which contributes to diverse developmental and degenerative disorders categorized as ciliopathies, which include polycystic kidney disease (PKD), nephronophthisis, retinitis pigmentosa, Bardet-Biedl syndrome, Joubert syndrome, and Meckel syndrome [68]. 
Table 1 Human disorders linked to centrosome-phagy

\begin{tabular}{|c|c|c|}
\hline \multicolumn{2}{|c|}{ Centrosome-phagy-associated human disorders } & \multirow{2}{*}{$\begin{array}{l}\text { Relevant proteins } \\
\text { OFD1 [98-100] }\end{array}$} \\
\hline Ciliopathies & Polycystic kidney disease, retinitis pigmentosa, Joubert syndrome & \\
\hline & Polycystic kidney disease, Bardet-Biedl syndrome, Joubert syndrome, Meckel syndrome & PCM1 [69-71, 101] \\
\hline Ageing & Huntington disease & PCM1 [102] \\
\hline \multirow[t]{3}{*}{ Cancer } & Thyroid, renal, breast, ovarian and colon cancer & Cep55 $[57,95,103-105]$ \\
\hline & Neuroblastoma & Cep63 [97] \\
\hline & Breast cancer & Cep131 [49] \\
\hline
\end{tabular}

Evidences suggest that both mislocalization and depletion of PCM1 can lead to suppression of ciliogenesis. Mutation or knockdown of BBS4 can cause PCM1 to be mislocalized, thereby inhibiting ciliogenesis in vivo and in vitro [69, 70]. And mutation of Cep290, which is the inducer of Joubert syndrome and associated with Meckel syndrome and Bardet-Biedl syndrome, depletes PCM1 from the centrosome to reduces ciliogenesis [71]. Likewise, autophagy regulates ciliogenesis by removing cilia-related proteins to ensure the proper length of cilia. This phenomenon suggest the potential for modulation of autophagy as a new therapeutic opportunity in ciliogenesis-related diseases [72]. As previously mentioned, the ciliopathy-related protein OFD1 located in centriolar satellites is degraded via autophagy to promote primary cilium biogenesis in MEFs and retinal pigment epithelium (RPE) cells [42]. PKD is a representative ciliopathy caused by mutations in the PKD1 or PKD2 gene [73]. Evidences show that congenital PKD mice are defective in autophagy. Meanwhile, suppression of autophagy is associated with defective cilia, and various autophagyinducing agents could protect against PKD [73]. These evidences further indicate that autophagy is involved in cilia formation.

In summary, centrosome-phagy may potentially contribute to the ability of centriolar satellites to exert proper function. However, the detailed mechanisms by which inhibited autophagy is associated with decreased autophagy in diverse ciliopathies and conditions with defective centrosomes remain unclear.

\section{Ageing}

Ageing is a natural biological process of all living organisms, the characteristics of which include disruptions in cellular metabolism and function that change with time and lead to permanent cell cycle arrest and cell death [74].

Direct evidence supports a causal link between centrosome aberrations and ageing-related diseases [75]. The centrosomes are fragmented in cells undergoing replicative senescence or premature senescence induced by oxidative stress [76], accompanied by p53 centrosome localization and phosphorylation at Ser 15 [60]. And centrosome fragmentation and the initiation of premature senescence can be caused by the disruption of core PCM components neural precursor cell expressed developmentally down-regulated protein 1 (NEDD1) and Cep192 [76]. Meanwhile, percentcentrin can be recruited to PCM by PCM1. Exit from the cell cycle can be induced by inhibition of percentenrin or PCM1, accompanied by increased expression of cellular $\beta$-galactosidase, a hallmark of cellular senescence [77]. These evidences indicating that the progression of cellular senescence can be promoted by centrosome defects. In addition, it has been established that autophagy-driven homeostatic restorations determine the lifespan of several model organisms. Evidences show that autophagy dysfunction occurs in ageing tissues and several aging-related diseases and decreased autophagy leads to accelerated aging process [78]. Meanwhile, organelle-initiated autophagy, including mitophagy (mitochondrial autophagy) [79], ER-phagy [80], centrosome-phagy, etc., also inhibit the aging process. Similarly, organelle-initiated autophagy can degrade damaged organelles or organelle components to maintain organelle functions. A few studies have demonstrated that suppression of mitophagy is exhibited in senescent cells and leads to a defective mitochondrial network that might result in metabolic dysfunction during aging [81, 82]. Specifically, Alzheimer's disease and Parkinson's disease are primary ageing-related diseases [83]. Defective autophagy supports a pathogenic role of protein aggregation (Alzheimer disease-associated $\beta$-amyloid and Parkinson diseaseassociated SNCA/ $\alpha$-synuclein), which is the main pathological feature in neurodegenerative diseases [84]. As mentioned above, Cory, as a neuroprotective autophagy enhancer, promoted the clearance of $\beta$-amyloid and $\alpha$-synuclein (SNCA)/ by enhancing autophagy, and these effects dramatically rely on the centrosome-associated kinase PLK1 [52].

Therefore, it is speculated that centrosome-phagy defects contribute to the accumulation of centrosomal abnormalities to drive senescence. Furthermore, a potent 
therapeutic strategy that targets the connection between the centrosome and autophagy has the possibility to improve ageing-associated syndromes.

\section{Cancer}

Centrosome aberrations are commonly observed in many different cancers, including breast, prostate, colon, ovarian and pancreatic cancer, and multiple myeloma, nonHodgkin's and Hodgkin's lymphomas, acute and chronic myeloid leukaemia [85, 86]. The underlying molecular mechanisms of centrosome dysfunction and its effect on cancer have recently begun to be explored. First, abnormal centrosome structures are usually observed in cancer cells. Centriole size is usually increased and displays significant over-elongation in cancer cells. And the centriole over-elongation drives centriole amplification [87]. In addition, evidences show that larger centrosomes in cancer cells are associated with stronger aggressiveness [88]. Besides, the centrosome can be misshapen in the form of string-like elongated linear arrays, ring-like, amorphous, atypical filaments, and corkscrew in cancer cells. These structural defects in the centrosome can lead to the formation of false mitotic spindles, which contribute to chromosomal missegregation and aneuploidy [89]. Consistently, centrosome amplification lead to genome instability to cause tumorigenesis and is associated with high-grade tumors and a poor prognosis [85]. Moreover, centrosome amplification can enhance stem cell division in Drosophila without significantly affecting genetic stability [90]. Second, centrosome aberrations can also facilitate the dissemination of metastatic cells by disrupting tissue architecture and confer invasive properties. Recent studies have shown that extra centrosomes induce Rasrelated $\mathrm{C} 3$ botulinum toxin substrate 1 (RAC1) activation by increasing microtubule nucleation and then promote tumour invasion through RAC1 [91]. The extra centrosome-associated secretory pathway (ECASP) has been considered to contribute to significant changes by inducing the release of a variety of pro-invasive factors (IL-8 and growth differentiation factor 15 (GDF-15)) that are associated with tumorigenesis and tumour metastasis [92]. Finally, evidences showed that centrosome defects can induce tumor drug resistance through multiple pathways [93]. Centrosome amplification is induced by PLK4 overexpression and promotes chromosomal instability, leading to breast cancer cells resistance to tamoxifen and trastuzumab [94]. Mitotic slippage, which is described as the process of cells leave mitosis without completing a normal cell division and become tetraploid, can be induced by overexpression of Cep55 and enhance breast cancer resistance to chemotherapy drugs, especially docetaxel [95]. In addition, the ATP-binding cassette (ABC) transporters members, as efflux drug pumps, can be activated to induce drug resistance by the overexpression of centrosome protein NIMA related kinase 2 (NEK2), including $\mathrm{ABCB} 1$ (p-glycoprotein, MDR1), the multidrug resistance protein $A B C C 1$ (MRP1), and the breast cancer resistant protein ABCG2 (BCRP) $[94,96]$.

A strong connection between centrosome amplification and autophagy in cancer was recently demonstrated. Evidence suggests that overexpression of Cep63 in U2OS cells can lead to centrosome amplification and is also associated with aggressive malignancies [97]. As mentioned above, Cep63 can be degraded by autophagy to inhibit centrosome amplification [32]. Moreover, the results show that centrosome amplification causes an accumulation of autophagosomes by interfering with autophagic flux [20]. Meanwhile, selectively activated autophagy maintains chromosomal stability and centrosome number to suppress tumour progression [19]. Taken together, these findings show that centrosome abnormalities potentially inhibit the autophagic response to promote tumour progression. A novel precision medicine strategy targeting centrosome-phagy may be important for anti-tumour therapeutic exploitation.

\section{Conclusion and perspective}

Understanding the effect of centrosome-phagy is an important research direction that has been widely ignored. Although there is little evidence, the available data strongly support the opinion that autophagy is associated with the function and integrity of the centrosome. Based on the fact that several centrosome phagocytic receptors have been identified and may be more commonly identified in the future, the analysis of their biological functions can be a challenging task. They may work collaboratively or have specific functions during centrosomal autophagy responses. For example, Cep63, as a valuable regulator of the initiation of centriole duplication, can be degraded in autophagosomes to maintain centrosome number, while PCM1, as the structural scaffold around the centriole, recruits GABARAP-associated autophagosomes to retain the normal structure of the centrosome. It is likely that different receptors may also mediate different pathways to activate autophagy. Cep63 directly binds to p62 and sustains the location of UVRAG at the centrosome; in contrast, PCM1 mainly interacts with GABARAPs via the PCM1 LIR motif.

Understanding the molecular pathways responsible for the activation of centrosome-phagy is also challenging. Currently, little is known about the basic molecular mechanisms of centrosome-phagy. The multitudinous kinases involved in the duplication and function of the centrosome are attractive as potential targets of therapy but require further study. For example, PLK1 not only plays an important role in the centrosome cycle 
but also stimulates the autophagic response by decreasing the function of mTORC1 at lysosomes. In addition, p53 may connect centrosome-phagy and specific stress stimuli. However, the detailed effect of p53 on centrosome-phagy is still an open question. We think that exploring answers to these questions will provoke an exciting surge in research involving the relationship between autophagy, autophagy-related signalling, and diverse stress stimuli, which are all closely associated with proper centrosome function.

The role of centrosome-phagy in the pathogenesis of human diseases remains to be seriously considered. Centrosome-phagy regulates the elimination of disease-related proteins, which is relevant to the pathogenesis of numerous ciliopathies. Moreover, centrosome-phagy may also be involved in ageing-related diseases, so it may affect neurological functions directly or indirectly involved in the development of neurodegenerative diseases. Ultimately, studies on the potential interactions between centrosomes and autophagy could better elucidate the impact of centrosome-phagy on tumour progression. Due to the widespread distribution of centrosome-phagy in human disease, the identification of therapies related to centrosome-phagy is pivotal.

\begin{abstract}
Abbreviations
53BP1: P53-binding protein 1; Al: Androgen-insensitive; AMPK: AMP-activated protein kinase; Arp2/3: Actin-related proteins 2/3; ATG: Autophagy-related protein; ATM: Ataxia telangiectasia mutated; BBS4: Bardet-Biedl syndrome 4; BCl-2: B-cell lymphoma-2; BCI-XL: B-cell lymphoma-extra large; BICD2: BICD cargo adaptor 2; BRCT: BRCA1 C terminus; Cep: Centrosomal protein; Cory: Corynoxine; CMA: Chaperone-mediated autophagy; CPAP: Centrosomal P4.1 associated protein; cryo-ET: Cryo-electron tomography; CSs: Centriolar satellites; DNA: Deoxyribonucleic acid; WIPI: Double FYVE-containing protein 1; DDR: DNA damage response; ECASP: Extra centrosome-associated secretory pathway; GABARAPs: Gamma-aminobutyric acid receptor-associated protein; GDF-15: Growth differentiation factor 15; LC3: Light chain 3; LIR: LC3-interacting region; IFT88: Intraflagellar transport protein 88; MEF: Mouse embryonic fibroblasts; MIB1: Mind bomb 1; mTORC1: Mechanistic target of rapamycin complex 1; NBR1: Neighbor of BRCA1 gene 1 protein; NEDD1: Neural precursor cell expressed developmentally down-regulated protein 1; OFD1: Oralfacial-digital syndrome type 1; P70S6K: Protein S6 kinase and polypeptide 1; PCa: Castration-resistant prostate cancer; PCM: Pericentriolar material; PI3K: Phosphoinositide 3-kinase; PKD: Polycystic kidney disease; PLK1: Polo-like kinase 1; PLK4: Polo-like kinase 4; RAC1: Ras-related C3 botulinum toxin substrate 1; RAPTOR: Regulatory-associated protein of mTOR; RPE: Retinal pigment epitheliums; SNCA: a-Synuclein; SAS-6: Spindle assembly abnormal protein 6 homolog; STIL: SCL-interrupting locus protein; ULK: Unc-51 like autophagy activating kinase; USP28: Ubiquitin-specific protease 28; USP9X: Ubiquitin specific peptidase 9 X-linked; UVRAG: UV-irradiation-resistance-associated gene; WASP: Wiskott-Aldrich syndrome protein; WASH: WASP and Scar homologue; WIPI2:WD repeat domain phosphoinositide-interacting protein 2.
\end{abstract}

\section{Acknowledgements}

We thank a professional English editor (American Journal Experts) for assistance in improving the quality of language.

\section{Authors' contributions}

QW and SS performed and conceived the review. QW and XY wrote the manuscript. LL drew all the figures. SS assisted in improving the quality of language and supplying financial support. All authors read and approved the final manuscript.

\section{Funding}

This work was partially supported by a National Natural Science Foundation of China (NSFC) grant (Grant No. 81471781) and a National major scientific instruments and equipment development projects grant (Grant No. 2012YQ160203) to Dr. Shengrong Sun. This work was also supported by National Natural Science Foundation of China (NSFC) grant (Grant No. 81903166), Health commission of Hubei Province scientific research project (Grant No. WJ2019Q053) and a Natural Science Foundation of Hubei (Grant No. 2018CKB916) to Dr. Si Sun.

Availability of data and materials

Not applicable.

Ethics approval and consent to participate

Not applicable.

Consent for publication

Not applicable.

\section{Competing interests}

The authors declare that they have no competing interests.

\section{Author details}

${ }^{1}$ Department of Breast and Thyroid Surgery, Renmin Hospital of Wuhan University, 238 Ziyang Road, Wuhan 430060, Hubei, People's Republic of China. ${ }^{2}$ Center of Ultramicroscopic Pathology, Renmin Hospital of Wuhan University, Wuhan, Hubei, People's Republic of China. ${ }^{3}$ Department of Clinical Laboratory, Renmin Hospital of Wuhan University, 238 Ziyang Road, Wuhan 430060, Hubei, People's Republic of China.

Received: 7 October 2020 Accepted: 16 February 2021

Published online: 04 March 2021

\section{References}

1. Banterle N, Gonczy P. Centriole biogenesis: from identifying the characters to understanding the plot. Annu Rev Cell Dev Biol. 2017;33:23-49. https://doi.org/10.1146/annurev-cellbio-100616-060454.

2. Winey M, O'Toole E. Centriole structure. Phil Trans R Soc Lond B Biol Sci. 2014. https://doi.org/10.1098/rstb.2013.0457.

3. Guichard P, Hachet V, Majubu N, Neves A, Demurtas D, Olieric N, et al. Native architecture of the centriole proximal region reveals features underlying its 9-fold radial symmetry. Curr Biol. 2013;23(17):1620-8. https://doi.org/10.1016/j.cub.2013.06.061.

4. Kobayashi T, Dynlacht BD. Regulating the transition from centriole to basal body. J Cell Biol. 2011;193(3):435-44. https://doi.org/10.1083/ jcb.201101005.

5. Woodruff JB, Wueseke O, Hyman AA. Pericentriolar material structure and dynamics. Phil Trans R Soc Lond B Biol Sci. 2014. https://doi. org/10.1098/rstb.2013.0459.

6. Hirono M. Cartwheel assembly. Phil Trans R Soc Lond B Biol Sci. 2014. https://doi.org/10.1098/rstb.2013.0458.

7. Kumari A, Panda D. Regulation of microtubule stability by centrosomal proteins. IUBMB Life. 2018;70(7):602-11. https://doi.org/10.1002/ iub. 1865.

8. Firat-Karalar EN, Stearns T. The centriole duplication cycle. Phil Trans R Soc Lond B Biol Sci. 2014. https://doi.org/10.1098/rstb.2013.0460.

9. Piel M, Meyer P, Khodjakov A, Rieder CL, Bornens M. The respective contributions of the mother and daughter centrioles to centrosome activity and behavior in vertebrate cells. J Cell Biol. 2000;149(2):317-30. https://doi.org/10.1083/jcb.149.2.317.

10. Fu J, Hagan IM, Glover DM. The centrosome and its duplication cycle. Cold Spring Harb Perspect Biol. 2015;7(2):a015800. https://doi. org/10.1101/cshperspect.a015800.

11. Schatten H, Sun Q-Y. Functions and dysfunctions of the mammalian centrosome in health, disorders, disease, and aging. Histochem Cell Biol. 2018;150(4):303-25. https://doi.org/10.1007/s00418-018-1698-1. 
12. Gambarotto D, Basto R. Consequences of numerical centrosome defects in development and disease. In: Lüders J, editor. The microtubule cytoskeleton: organisation, function and role in disease. Vienna: Springer Vienna; 2016. p. 117-49.

13. Remo A, Li X, Schiebel E, Pancione M. The centrosome linker and its role in cancer and genetic disorders. Trends Mol Med. 2020;26(4):380-93. https://doi.org/10.1016/j.molmed.2020.01.011.

14. Bolhy S, Bouhlel I, Dultz E, Nayak T, Zuccolo M, Gatti X, et al. A Nup133-dependent NPC-anchored network tethers centrosomes to the nuclear envelope in prophase. J Cell Biol. 2011;192(5):855-71. https://doi.org/10.1083/jcb.201007118.

15. Tang CJ, Fu RH, Wu KS, Hsu WB, Tang TK. CPAP is a cell-cycle regulated protein that controls centriole length. Nat Cell Biol. 2009;11(7):82531. https://doi.org/10.1038/ncb1889.

16. Holland AJ, Fachinetti D, Zhu Q, Bauer M, Verma IM, Nigg EA, et al. The autoregulated instability of Polo-like kinase 4 limits centrosome duplication to once per cell cycle. Genes Dev. 2012;26(24):2684-9. https://doi.org/10.1101/gad.207027.112.

17. Donthamsetty S, Brahmbhatt M, Pannu V, Rida PC, Ramarathinam S, Ogden A, et al. Mitochondrial genome regulates mitotic fidelity by maintaining centrosomal homeostasis. Cell Cycle. 2014;13(13):205663. https://doi.org/10.4161/cc.29061.

18. Godinho SA, Kwon M, Pellman D. Centrosomes and cancer: how cancer cells divide with too many centrosomes. Cancer Metastasis Rev. 2009;28(1-2):85-98. https://doi.org/10.1007/s10555-008-9163-6.

19. Mathew R, Kongara S, Beaudoin B, Karp CM, Bray K, Degenhardt K, et al. Autophagy suppresses tumor progression by limiting chromosomal instability. Genes Dev. 2007;21(11):1367-81. https://doi. org/10.1101/gad.1545107.

20. Denu RA, Kaur G, Sass MM, Lakkaraju A, Burkard ME. Centrosome amplification in cancer disrupts autophagy and sensitizes to autophagy inhibition. Mol Cancer Res. 2020;18(1):33-45. https://doi. org/10.1158/1541-7786.MCR-19-0509.

21. Hori A, Toda T. Regulation of centriolar satellite integrity and its physiology. Cell Mol Life Sci CMLS. 2017;74(2):213-29. https://doi. org/10.1007/s00018-016-2315-x.

22. Galluzzi L, Baehrecke EH, Ballabio A, Boya P, Bravo-San Pedro JM, Cecconi $F$, et al. Molecular definitions of autophagy and related processes. EMBO J. 2017;36(13):1811-36. https://doi.org/10.15252/ embj.201796697.

23. Karanasios E, Walker SA, Okkenhaug H, Manifava M, Hummel E, Zimmermann $\mathrm{H}$, et al. Autophagy initiation by ULK complex assembly on ER tubulovesicular regions marked by ATG9 vesicles. Nat Commun. 2016;7:12420. https://doi.org/10.1038/ncomms12420.

24. Dooley HC, Razi M, Polson HEJ, Girardin SE, Wilson MI, Tooze SA. WIPI2 links LC3 conjugation with PI3P, autophagosome formation, and pathogen clearance by recruiting Atg12-5-16L1. Mol Cell. 2014;55(2):238-52. https://doi.org/10.1016/j.molcel.2014.05.021.

25. Schaaf MBE, Keulers TG, Vooijs MA, Rouschop KMA. LC3/GABARAP family proteins: autophagy-(un)related functions. FASEB J. 2016;30(12):3961-78. https://doi.org/10.1096/fj.201600698R.

26. Slobodkin MR, Elazar Z. The Atg8 family: multifunctional ubiquitinlike key regulators of autophagy. Essays Biochem. 2013;55:51-64. https://doi.org/10.1042/bse0550051.

27. Nguyen TN, Padman BS, Usher J, Oorschot V, Ramm G, Lazarou M. Atg8 family LC3/GABARAP proteins are crucial for autophagosomelysosome fusion but not autophagosome formation during PINK1/ Parkin mitophagy and starvation. J Cell Biol. 2016;215(6):857-74.

28. Velikkakath AKG, Nishimura T, Oita E, Ishihara N, Mizushima NJMBotC. Mammalian Atg2 proteins are essential for autophagosome formation and important for regulation of size and distribution of lipid droplets. Mol Biol Cell. 2012;23(5):896-909.

29. Zhao H, Zhu L, Zhu Y, Cao J, Li S, Huang Q, et al. The Cep63 paralogue Deup1 enables massive de novo centriole biogenesis for vertebrate multiciliogenesis. Nat Cell Biol. 2013;15(12):1434-44. https://doi. org/10.1038/ncb2880.

30. Brown NJ, Marjanovic M, Luders J, Stracker TH, Costanzo V. Cep63 and cep152 cooperate to ensure centriole duplication. PLOS ONE. 2013;8(7):e69986. https://doi.org/10.1371/journal.pone.0069986.

31. Strnad P, Leidel S, Vinogradova T, Euteneuer U, Khodjakov A, Gonczy P. Regulated HsSAS-6 levels ensure formation of a single procentriole per centriole during the centrosome duplication cycle. Dev Cell. 2007;13(2):203-13. https://doi.org/10.1016/j.devcel.2007.07.004.

32. Watanabe Y, Honda S, Konishi A, Arakawa S, Murohashi M, Yamaguchi $\mathrm{H}$, et al. Autophagy controls centrosome number by degrading Cep63. Nat Commun. 2016;7:13508. https://doi.org/10.1038/ncomms13508.

33. Zhao Z, Oh S, Li D, Ni D, Pirooz SD, Lee JH, et al. A dual role for UVRAG in maintaining chromosomal stability independent of autophagy. Dev Cell. 2012;22(5):1001-16. https://doi.org/10.1016/j.devcel.2011.12.027.

34. Wu S, He Y, Qiu X, Yang W, Liu W, Li X, et al. Targeting the potent Beclin 1-UVRAG coiled-coil interaction with designed peptides enhances autophagy and endolysosomal trafficking. Proc Natl Acad Sci USA. 2018;115(25):E5669-78. https://doi.org/10.1073/pnas.1721173115.

35. Wen F, Armstrong N, Hou W, Cruz-Cosme R, Obwolo LA, Ishizuka K, et al. Zika virus increases mind bomb 1 levels, causing degradation of pericentriolar material 1 (PCM1) and dispersion of PCM1-containing granules from the centrosome. J Biol Chem. 2019;294(49):18742-55. https://doi.org/10.1074/jbc.RA119.010973.

36. Wang Q, Tang Y, Xu Y, Xu S, Jiang Y, Dong Q, et al. The X-linked deubiquitinase USP9X is an integral component of centrosome. J Biol Chem. 2017;292(31):12874-84. https://doi.org/10.1074/jbc.M116.769943.

37. Farina F, Gaillard J, Guerin C, Coute Y, Sillibourne J, Blanchoin L, et al. The centrosome is an actin-organizing centre. Nat Cell Biol. 2016;18(1):6575. https://doi.org/10.1038/ncb3285.

38. Holdgaard SG, Cianfanelli V, Cecconi F. Cloud hunting: doryphagy, a form of selective autophagy that degrades centriolar satellites. Autophagy. 2020;16(2):379-81. https://doi.org/10.1080/15548 627.2019.1703356.

39. Joachim J, Jefferies HB, Razi M, Frith D, Snijders AP, Chakravarty P, et al. Activation of ULK kinase and autophagy by GABARAP trafficking from the centrosome is regulated by WAC and GM130. Mol Cell. 2015;60(6):899-913. https://doi.org/10.1016/j.molcel.2015.11.018.

40. Joachim J, Razi M, Judith D, Wirth M, Calamita E, Encheva V, et al. Centriolar satellites control GABARAP ubiquitination and GABARAP-mediated autophagy. Curr Biol. 2017;27(14):2123-36 e7. https://doi.org/10.1016/j. cub.2017.06.021.

41. Holdgaard SG, Cianfanelli V, Pupo E, Lambrughi M, Lubas M, Nielsen $J C$, et al. Selective autophagy maintains centrosome integrity and accurate mitosis by turnover of centriolar satellites. Nat Commun. 2019;10(1):4176. https://doi.org/10.1038/s41467-019-12094-9.

42. Tang Z, Lin MG, Stowe TR, Chen S, Zhu M, Stearns T, et al. Autophagy promotes primary ciliogenesis by removing OFD1 from centriolar satellites. Nature. 2013;502(7470):254-7. https://doi.org/10.1038/nature1260 6.

43. Field M, Scheffer IE, Gill D, Wilson M, Christie L, Shaw M, et al. Expanding the molecular basis and phenotypic spectrum of X-linked Joubert syndrome associated with OFD1 mutations. Eur J Hum Genet. 2012;20(7):806-9. https://doi.org/10.1038/ejhg.2012.9.

44. Ferrante MI, Zullo A, Barra A, Bimonte S, Messaddeq N, Studer M, et al. Oral-facial-digital type I protein is required for primary cilia formation and left-right axis specification. Nat Genet. 2006;38(1):112-7. https:// doi.org/10.1038/ng1684.

45. Lopes CA, Prosser SL, Romio L, Hirst RA, O'Callaghan C, Woolf AS, et al. Centriolar satellites are assembly points for proteins implicated in human ciliopathies, including oral-facial-digital syndrome 1. J Cell Sci. 2011;124(Pt 4):600-12. https://doi.org/10.1242/jcs.077156.

46. Staples CJ, Myers KN, Beveridge RD, Patil AA, Lee AJ, Swanton C, et al. The centriolar satellite protein Cep131 is important for genome stability. J Cell Sci. 2012;125(Pt 20):4770-9. https://doi.org/10.1242/jcs.10405 9.

47. Villumsen BH, Danielsen JR, Povlsen L, Sylvestersen KB, Merdes A, Beli $P$, et al. A new cellular stress response that triggers centriolar satellite reorganization and ciliogenesis. EMBO J. 2013;32(23):3029-40. https:// doi.org/10.1038/emboj.2013.223.

48. Kim DH, Ahn JS, Han HJ, Kim HM, Hwang J, Lee KH, et al. Cep131 overexpression promotes centrosome amplification and colon cancer progression by regulating Plk4 stability. Cell Death Dis. 2019;10(8):570. https://doi.org/10.1038/s41419-019-1778-8.

49. Li X, Song N, Liu L, Liu X, Ding X, Song X, et al. USP9X regulates centrosome duplication and promotes breast carcinogenesis. Nat Commun. 2017;8:14866. https://doi.org/10.1038/ncomms14866. 
50. Kuo TC, Chen CT, Baron D, Onder TT, Loewer S, Almeida S, et al. Midbody accumulation through evasion of autophagy contributes to cellular reprogramming and tumorigenicity. Nat Cell Biol. 2011;13(10):121423. https://doi.org/10.1038/ncb2332.

51. Kumar S, Sharma AR, Sharma G, Chakraborty C, Kim J. PLK-1: angel or devil for cell cycle progression. Biochem Biophys Acta. 2016;1865(2):190-203. https://doi.org/10.1016/j.bbcan.2016.02.003.

52. Chen LL, Wang YB, Song JX, Deng WK, Lu JH, Ma LL, et al. Phosphoproteome-based kinase activity profiling reveals the critical role of MAP2K2 and PLK1 in neuronal autophagy. Autophagy. 2017;13(11):1969-80. https://doi.org/10.1080/15548627.2017.1371393.

53. Ruf S, Heberle AM, Langelaar-Makkinje M, Gelino S, Wilkinson D, Gerbeth C, et al. PLK1 (polo like kinase 1) inhibits MTOR complex 1 and promotes autophagy. Autophagy. 2017;13(3):486-505. https://doi. org/10.1080/15548627.2016.1263781.

54. Deeraksa A, Pan J, Sha Y, Liu XD, Eissa NT, Lin SH, et al. Plk1 is upregulated in androgen-insensitive prostate cancer cells and its inhibition leads to necroptosis. Oncogene. 2013;32(24):2973-83. https://doi. org/10.1038/onc.2012.309.

55. Tao YF, Li ZH, Du WW, Xu LX, Ren JL, Li XL, et al. Inhibiting PLK1 induces autophagy of acute myeloid leukemia cells via mammalian target of rapamycin pathway dephosphorylation. Oncol Rep. 2017;37(3):141929. https://doi.org/10.3892/or.2017.5417.

56. Aylon Y, Oren M. p53: guardian of ploidy. Mol Oncol. 2011;5(4):315-23. https://doi.org/10.1016/j.molonc.2011.07.007.

57. Chang YC, Wu CH, Yen TC, Ouyang P. Centrosomal protein 55 (Cep55) stability is negatively regulated by p53 protein through Polo-like kinase 1 (Plk1). J Biol Chem. 2012;287(6):4376-85. https://doi.org/10.1074/jbc. M111.289108.

58. Marjanovic M, Sanchez-Huertas C, Terre B, Gomez R, Scheel JF, Pacheco $\mathrm{S}$, et al. CEP63 deficiency promotes p53-dependent microcephaly and reveals a role for the centrosome in meiotic recombination. Nat Commun. 2015;6:7676. https://doi.org/10.1038/ncomms8676.

59. Nam HJ, van Deursen JM. Cyclin B2 and p53 control proper timing of centrosome separation. Nat Cell Biol. 2014;16(6):538-49. https://doi. org/10.1038/ncb2952.

60. Ohshima S. Centrosome aberrations associated with cellular senescence and p53 localization at supernumerary centrosomes. Oxid Med Cell Longev. 2012;2012:217594. https://doi.org/10.1155/2012/217594.

61. Oricchio E, Saladino C, lacovelli S, Soddu S, Cundari E. ATM is activated by default in mitosis, localizes at centrosomes and monitors mitotic spindle integrity. Cell Cycle. 2006;5(1):88-92. https://doi.org/10.4161/ cc.5.1.2269.

62. Contadini C, Monteonofrio L, Virdia I, Prodosmo A, Valente D, Chessa $L$, et al. p53 mitotic centrosome localization preserves centrosome integrity and works as sensor for the mitotic surveillance pathway. Cell Death Dis. 2019;10(11):850. https://doi.org/10.1038/s41419-019-2076-1.

63. Soussi T, Kroemer G. TP53 and 53BP1 reunited. Trends Cell Biol. 2017:27(5):311-3.

64. Maiuri MC, Galluzzi L, Morselli E, Kepp O, Malik SA, Kroemer G. Autophagy regulation by p53. Curr Opin Cell Biol. 2010;22(2):181-5. https://doi.org/10.1016/j.ceb.2009.12.001.

65. Conduit PT, Wainman A, Raff JW. Centrosome function and assembly in animal cells. Nat Rev Mol Cell Biol. 2015;16(10):611-24. https://doi. org/10.1038/nrm4062.

66. Nicastro D, Schwartz C, Pierson J, Gaudette R, Porter ME, McIntosh JR. The molecular architecture of axonemes revealed by cryoelectron tomography. Science (New York, NY). 2006;313(5789):944-8. https://doi. org/10.1126/science.1128618.

67. Sánchez I, Dynlacht BD. Cilium assembly and disassembly. Nat Cell Biol. 2016;18(7):711-7. https://doi.org/10.1038/ncb3370.

68. Hildebrandt F, Benzing T, Katsanis N. Ciliopathies. N Engl J Med. 2011;364(16):1533-43. https://doi.org/10.1056/NEJMra1010172.

69. Kulaga HM, Leitch CC, Eichers ER, Badano JL, Lesemann A, Hoskins $\mathrm{BE}$, et al. Loss of BBS proteins causes anosmia in humans and defects in olfactory cilia structure and function in the mouse. Nat Genet. 2004;36(9):994-8.

70. Nachury MV, Loktev AV, Zhang Q, Westlake CJ, Peränen J, Merdes A, et al. A core complex of BBS proteins cooperates with the GTPase Rab8 to promote ciliary membrane biogenesis. Cell. 2007;129(6):1201-13.
71. Kim J, Krishnaswami SR, Gleeson JG. CEP290 interacts with the centriolar satellite component PCM-1 and is required for Rab8 localization to the primary cilium. Hum Mol Genet. 2008;17(23):3796-805. https://doi. org/10.1093/hmg/ddn277.

72. Orhon I, Dupont N, Pampliega O, Cuervo AM, Codogno P. Autophagy and regulation of cilia function and assembly. Cell Death Differ. 2015;22(3):389-97. https://doi.org/10.1038/cdd.2014.171.

73. Ravichandran K, Edelstein CL. Polycystic kidney disease: a case of suppressed autophagy? Semin Nephrol. 2014;34(1):27-33. https://doi. org/10.1016/j.semnephrol.2013.11.005.

74. Herranz N, Gil J. Mechanisms and functions of cellular senescence. J Clin Investig. 2018;128(4):1238-46. https://doi.org/10.1172/JC195148.

75. Wu Q, Li B, Liu L, Sun S, Sun S. Centrosome dysfunction: a link between senescence and tumor immunity. Signal Transduct Target Ther. 2020;5(1):107. https://doi.org/10.1038/s41392-020-00214-7.

76. Manning JA, Kumar S. A potential role for NEDD1 and the centrosome in senescence of mouse embryonic fibroblasts. Cell Death Dis. 2010;1:e35. https://doi.org/10.1038/cddis.2010.12.

77. Srsen V, Gnadt N, Dammermann A, Merdes A. Inhibition of centrosome protein assembly leads to p53-dependent exit from the cell cycle. J Cell Biol. 2006;174(5):625-30. https://doi.org/10.1083/jcb.200606051.

78. He L-q, Lu J-h, Yue Z-y. Autophagy in ageing and ageing-associated diseases. Acta Pharmacol Sin. 2013;34(5):605-11. https://doi.org/10.1038/ aps.2012.188.

79. Fivenson EM, Lautrup S, Sun N, Scheibye-Knudsen M, Stevnsner T, Nilsen $\mathrm{H}$, et al. Mitophagy in neurodegeneration and aging. Neurochem Int. 2017;109:202-9. https://doi.org/10.1016/j.neuint.2017.02.007.

80. Hübner CA, Dikic I. ER-phagy and human diseases. Cell Death Differ. 2020;27(3):833-42. https://doi.org/10.1038/s41418-019-0444-0.

81. Stead ER, Castillo-Quan JI, Miguel VEM, Lujan C, Ketteler R, Kinghorn KJ, et al. Agephagy-adapting autophagy for health during aging. Front Cell Dev Biol. 2019. https://doi.org/10.3389/fcell.2019.00308.

82. Dorr JR, Yu Y, Milanovic M, Beuster G, Zasada C, Dabritz JH, et al. Synthetic lethal metabolic targeting of cellular senescence in cancer therapy. Nature. 2013;501 (7467):421-5. https://doi.org/10.1038/natur e12437.

83. Hou Y, Dan X, Babbar M, Wei Y, Hasselbalch SG, Croteau DL, et al. Ageing as a risk factor for neurodegenerative disease. Nat Rev Neurol. 2019;15(10):565-81. https://doi.org/10.1038/s41582-019-0244-7.

84. Espay AJ, Vizcarra JA, Marsili L, Lang AE, Simon DK, Merola A, et al. Revisiting protein aggregation as pathogenic in sporadic Parkinson and Alzheimer diseases. Neurology. 2019;92(7):329-37. https://doi. org/10.1212/WNL.0000000000006926.

85. Godinho SA, Pellman D. Causes and consequences of centrosome abnormalities in cancer. Phil Trans R Soc Lond B Biol Sci. 2014. https:// doi.org/10.1098/rstb.2013.0467.

86. Gonczy P. Centrosomes and cancer: revisiting a long-standing relationship. Nat Rev Cancer. 2015;15(11):639-52. https://doi.org/10.1038/nrc39 95.

87. Marteil G, Guerrero A, Vieira AF, de Almeida BP, Machado P, Mendonça $\mathrm{S}$, et al. Over-elongation of centrioles in cancer promotes centriole amplification and chromosome missegregation. Nat Commun. 2018:9(1):1258. https://doi.org/10.1038/s41467-018-03641-x.

88. Ogden A, Rida PCG, Aneja RJERC. Centrosome amplification: a suspect in breast cancer and racial disparities. Endocr Related Cancer. 2017. https://doi.org/10.1530/ERC-17-0072.

89. Chan JY. A clinical overview of centrosome amplification in human cancers. Int J Biol Sci. 2011;7(8):1122-44. https://doi.org/10.7150/ ijbs.7.1122.

90. Basto R, Brunk K, Vinadogrova T, Peel N, Franz A, Khodjakov A, et al. Centrosome amplification can initiate tumorigenesis in flies. Cell. 2008;133(6):1032-42. https://doi.org/10.1016/j.cell.2008.05.039.

91. Godinho SA, Picone R, Burute M, Dagher R, Su Y, Leung CT, et al. Oncogene-like induction of cellular invasion from centrosome amplification. Nature. 2014;510(7503):167-71. https://doi.org/10.1038/nature13277.

92. Arnandis T, Monteiro P, Adams SD, Bridgeman VL, Rajeeve V, Gadaleta $\mathrm{E}$, et al. Oxidative stress in cells with extra centrosomes drives noncell-autonomous invasion. Dev Cell. 2018;47(4):409-24 e9. https://doi. org/10.1016/j.devcel.2018.10.026. 
93. Jia Z-H, Wang X-G, Zhang H. Overcome cancer drug resistance by targeting epigenetic modifications of centrosome. Cancer Drug Resist. 2019;2:210-24

94. Marina M, Saavedra HI. Nek2 and Plk4: prognostic markers, drivers of breast tumorigenesis and drug resistance. Front Biosci (Landmark Ed). 2014;19:352-65.

95. Kalimutho M, Sinha D, Jeffery J, Nones K, Srihari S, Fernando WC, et al. CEP55 is a determinant of cell fate during perturbed mitosis in breast cancer. EMBO Mol Med. 2018. https://doi.org/10.15252/emmm.20170 8566.

96. Zhou W, Yang Y, Xia J, Wang H, Salama ME, Xiong W, et al. NEK2 induces drug resistance mainly through activation of efflux drug pumps and is associated with poor prognosis in myeloma and other cancers. Cancer Cell. 2013;23(1):48-62. https://doi.org/10.1016/j.ccr.2012.12.001.

97. Löffler H, Fechter A, Matuszewska M, Saffrich R, Mistrik M, Marhold J, et al. Cep63 recruits $C \mathrm{dk} 1$ to the centrosome: implications for regulation of mitotic entry, centrosome amplification, and genome maintenance. Cancer Res. 2011;71(6):2129. https://doi.org/10.1158/0008-5472. CAN-10-2684.

98. Webb TR, Parfitt DA, Gardner JC, Martinez A, Bevilacqua D, Davidson AE, et al. Deep intronic mutation in OFD1, identified by targeted genomic next-generation sequencing, causes a severe form of $X$-linked retinitis pigmentosa (RP23). Hum Mol Genet. 2012;21(16):3647-54. https://doi. org/10.1093/hmg/dds194.

99. Coene KLM, Roepman R, Doherty D, Afroze B, Kroes HY, Letteboer SJF, et al. OFD1 is mutated in X-linked Joubert syndrome and interacts with LCA5-encoded lebercilin. Am J Hum Genet. 2009;85(4):465-81. https:// doi.org/10.1016/j.ajhg.2009.09.002.
100. Wentzensen IM, Johnston JJ, Patton JH, Graham JM, Sapp JC, Biesecker LG. Exome sequencing identifies a mutation in OFD1 in a male with Joubert syndrome, orofaciodigital spectrum anomalies and complex polydactyly. Hum Genome Var. 2016;3:15069. https://doi.org/10.1038/ hgv.2015.69.

101. Skalická K, Hrčková G, Vaská A, Baranyaiová Á, Kovács L. Genetic defects in ciliary genes in autosomal dominant polycystic kidney disease. World J Nephrol. 2018;7(2):65-70. https://doi.org/10.5527/wjn.v7.i2.65.

102. Li S, Li XJ. A huntingtin-HAP1-PCM1 pathway in ciliogenesis. Expert Rev Proteomics. 2012;9(1):17-9. https://doi.org/10.1586/epr.11.72.

103. Cheng WY, Ou Yang TH, Anastassiou D. Biomolecular events in cancer revealed by attractor metagenes. PLoS Comput Biol. 2013;9(2):e1002920. https://doi.org/10.1371/journal.pcbi.1002920.

104. Jones J, Otu H, Spentzos D, Kolia S, Inan M, Beecken WD, et al. Gene signatures of progression and metastasis in renal cell cancer. Clin Cancer Res. 2005;11(16):5730-9. https://doi.org/10.1158/1078-0432. Ccr-04-2225.

105. Montero-Conde C, Martín-Campos JM, Lerma E, Gimenez G, MartínezGuitarte JL, Combalía N, et al. Molecular profiling related to poor prognosis in thyroid carcinoma. Combining gene expression data and biological information. Oncogene. 2008;27(11):1554-61. https://doi. org/10.1038/sj.onc.1210792.

\section{Publisher's Note}

Springer Nature remains neutral with regard to jurisdictional claims in published maps and institutional affiliations.
Ready to submit your research? Choose BMC and benefit from:

- fast, convenient online submission

- thorough peer review by experienced researchers in your field

- rapid publication on acceptance

- support for research data, including large and complex data types

- gold Open Access which fosters wider collaboration and increased citations

- maximum visibility for your research: over $100 \mathrm{M}$ website views per year

At $\mathrm{BMC}$, research is always in progress.

Learn more biomedcentral.com/submissions 